\title{
Review of basic trends in cryotherapy applications for horse injuries
}

\author{
[Revisão das tendências básicas em aplicações de crioterapia em lesões em cavalos] \\ O. Sobol $^{1}$, V. Domatskiy ${ }^{2}$, E. Koneva ${ }^{3}$, K. Nifontov ${ }^{4}$, M. Savvinova ${ }^{4}$ \\ ${ }^{1}$ Kherson State Agricultural University, Kherson, Ukraine. \\ ${ }^{2}$ Northern Trans-Ural State Agricultural University, Tyumen, Russian Federation \\ ${ }^{3}$ I.M. Sechenov First Moscow State Medical University (Sechenov University), Moscow, Russian Federation \\ ${ }^{4}$ Yakut State Agricultural Academy, Yakutsk, Russian Federation
}

\begin{abstract}
While solving the problem of sport horses' pathologies it is important to choose safe and environmentally friendly methods, including cryotherapy, which is the topic of our research. The use of cryotherapy is a promising means of treatment of primary injury, rehabilitation in post-traumatic conditions and in chronic injuries. Prospects of cryotherapy applications in horse breeding, in particular in sports and prize areas, were researched. It was found out that modern sport horses training and their involvement in competitions is associated with serious stress on their locomotor system and maximum mobilization of all body systems, which overstrains certain muscle groups, determines increased probability and severity of injury incidence, reduction of sport longevity and worse performance in competitions.
\end{abstract}

Keywords: Cryotherapy, sport horses, racing horses, trotter horses, injury rate, arthrosis

\section{RESUMO}

Na resolução do problema das patologias dos cavalos esportivos é importante escolher métodos seguros e ecológicos, incluindo a crioterapia, que é o tópico desta pesquisa. O uso da crioterapia é um meio promissor no tratamento de lesões primárias, reabilitação em condições pós-traumáticas e lesões crônicas. Foram pesquisadas as perspectivas de aplicações da crioterapia na criação de cavalos, particularmente em esportes e prêmios. Verificou-se que o treinamento moderno de cavalos esportivos e seu envolvimento em competições está associado com severo estresse sobre seu sistema locomotor e mobilização máxima de todos os sistemas corporais, que sobrecarregam certos grupos musculares, determinam maior probabilidade e severidade da incidência de lesões, e reduzem a longevidade no esporte e pior desempenho em competições.

Palavras-chave: crioterapia, cavalos esportivos, cavalos de corrida, cavalos de trote, taxa de lesões, artrose

\section{INTRODUCTION}

Cryotherapy is a medical treatment that involves general or local use of cold. The use of healing properties of low temperatures has a long history - thus, 2,500 years BC the Egyptians used cold for medical purposes; this technique is also mentioned in the writings of Hippocrates, and later, Nikolai Pirogov. Modern cryotherapy techniques are based on the works of Japanese researcher T. Yamauchi, who in 1980 created a chamber that allowed conducting cryotherapy

Recebido em 10 de janeiro de 2019

Aceito em 15 de agosto de 2019

E-mail: olyasobol.uni@gmail.com sessions due to liquid nitrogen evaporation. Under the guidance of R. Fricke cryotherapy applications were researched in Germany in 1982, and later cryotherapy application protocols in medical therapy were formulated (Geroeva $e t$ al., 2005; The history of cryotherapy..., 2018). At the end of the 20th century certain areas of medical therapy where cryotherapy was used most intensively were identified, namely:

- traumatology, arthrology, rheumatology (injury rehabilitation, treatment of musculoskeletal disorders) 
- dermatology - treatment of acute and chronic inflammatory conditions, secondary degenerative skin lesions (psoriasis, neurodermatitis, seborrhea, eczema, scleroderma, lichen planus);

- gastroenterology - treatment of chronic gastritis, peptic ulcer, chronic cholecystitis;

- preventive medicine - prevention and treatment of asthenic disorders, cold prevention and maintenance of homeostasis in the body;

- pulmonology - treatment of asthma, chronic bronchitis;

- neurology - treatment of nervous system disorders (cerebral palsy, multiple sclerosis, myasthenia, migraine, parkinsonism, etc.), manifestations of systemic diseases or injuries (pain, spastic, paretic, reflectory and neurodegenerative syndromes) (Baranov and Kidalov, 1999).

Cryotherapy increases pain threshold and induces physiological changes. It affects hemodynamics (lowering the skin and muscle temperature due to vasoconstriction), metabolism (reducing ischemia due to hypoxia), and nervous control (decreasing nerve conduction rate and muscle tone). Cryotherapy may be used as shortterm (less than 15 minutes) or as long-term therapy (more than 20 minutes). To maximize its efficiency one should consider the intensity, as well as the environment of application (The history of cryotherapy..., 2018).

Thus, while assessing the difference between the maximum and the minimum temperature before and after cold exposure and the relative contrast (as compared to the average temperature of the selected area of interest before and after cooling, respectively), analysis showed that in both cases (for whole-body and local cryotherapy) similar rates of temperature contrast were obtained, but local therapy is cheaper and easier to use, while whole-body therapy can give more information about the state of soft tissues for the entire back (Cholewka et al., 2017; Herrmann et al.).

Cryotherapy applications are widely used in sports medicine. Sessions in a cryosauna take no more than three minutes, and can be repeated up to four times per day, catalyzing detoxification, normalizing athlete's emotional state, relieving fatigue and overalertness. It is best to take a cryotherapy session immediately after intense physical activity (Baranov et al., 2011). Shortterm reduction of individual performance after cryotherapy sessions can be used to intensify workouts. Within four hours after the session highly trained athletes have to put more effort to achieve their usual result, which makes them train harder. In addition, cryotherapy sessions improve the adjustment to local time during international competitions (Dinesh, 2015; Wójcik, 2017).

Analysis of the main trends in research into problems has shown that, in modern sport and prize horse breeding, the problem of reducing injuries and its negative impact remains relevant. Decreased performance, deterioration in the prospects for the sports and prize career of horses, the risk of death of horses are the main consequences of injury. Based on the prevalence of injuries and diseases of the musculoskeletal system, the question of choosing a strategy for the treatment and rehabilitation of horses arises. Increasing attention is being paid to safer methods of treatment and rehabilitation, in particular, cryotherapy, which has several advantages. Cryotherapy often surpasses the results of using other methods of exposure, especially in those areas where poor skin mobility prevents the closure of sutures. Usual surgical excision produces excessive blood loss, while cryotherapy usually leads to minimal hemorrhage. This is especially effective for older or debilitated patients. After cryotherapy, small scars usually remain, and the cosmetic effect is good (Russillo, 2018).

Thus, the use of cryotherapeutic techniques is a current trend to increase the effectiveness of treatment and rehabilitation of horses of sports and prize directions. Based on the study of the main publications, the goal of our research was formed. The study aims to substantiate the possibility of using the method of cryotherapy and cryogenic equipment for their treatment and rehabilitation by analyzing the experience of treatment and rehabilitation of injuries of horses of various directions. The main tasks of the research are:

- determine the features of injuries of horses of sports and prize directions in connection with their use;

- to identify the main directions of the successful application of cryotherapy technologies for treatment and rehabilitation; 
- to characterize the main types of cryotherapeutic techniques that are used in treatment to improve the health status and the quality of life of injured horses.

\section{MATERIALS AND METHODS}

Equestrian sport puts high requirements on ensuring health and high performance of sport horses in order to achieve high and stable results in various competitions. Athletic training in horses requires a high level of strength and endurance, and therefore presents a significant risk of overload and injuries, especially in the muscular and skeletal systems. The consequences can be quite detrimental, limiting the chances of achieving top sports result and possibly adversely affecting the horse's ability to function normally after the end of athletic career (Russillo, 2018).

Indeed, joint diseases are caused by injuries, and injury incidence in sport horses can be as high as $63.9 \%$ of the total number of affected animals. Therefore, considering strenuous exercise in equestrian sport, scientific inquiry should prioritize identifying the ways to revert destructive process in horses, searching for a prognostic criterion for the disease progression depending on the level of joint tissue destruction, as well as the positions determinative for further use of sport horses (Carlson et al., 1995).

Injury incidence in horse breeding remains the most important factor in the loss of athletic potential and the deterioration of athletic future and prize career prospects for horses. The most dangerous injury rate situation is in prize horse breeding. For example, in general, on the USA racetracks in 2015, 1.62 cases of severe injuries, often incompatible with life, accounted for 1,000 starts. At the same time, the injury rate on synthetic racetrack, with 1.18 cases per 1,000 starts, was least high (Injuries to horses..., 2016).

In 2017, on the USA and Canada racetracks the fatality rate in injured horses was reported at 1,61 cases per 1,000 races. Notably, the incidence (number of fatalities per 1,000 starts) varied depending on the track surface: on turf/grass - 1,36; on dirt - 1,74; on synthetic surface $-1,1(1,1)$. The highest percentage of severe injuries and fatalities in horses was reported for short-distance races, up to 1,200 meters (Alarming statistics..., 2018).

Any injury can significantly restrict or disrupt the horse's sports career, and sometimes even result in death. Every year up to $40 \%$ of horses involved in racing get injuries to flexor tendon. For racing horses in most cases this diagnosis is effectively career-ending. In classical types of equestrian sports (show-jumping, dressage, triathlon) the situation appears to be more optimistic at first glance, since the injury incidence is significantly lower (no more than $20 \%$ of animals) (Horse injuries..., 2014).

Among non-infectious diseases in sport horses it is muscles that are prone to frequent injury, which leads to unwelcome adjustments to the training schedule, limits the horse's athletic performance, or even may lead to the animal's withdrawal from training. Thus, in trotter and riding horses acute aseptic myositis of the shoulder girdle occurs in $18,2-41,5 \%$ of animals, whereas the pelvic girdle damage is reported in 18.5 - $26.8 \%$ of animals (Kalashnik, 1990).

In equestrian schools, every horse suffers from diseases 3 to 4 times per year on the average, and some sport horses under high-intensity training load can suffer from diseases up to 10 times per year. Out of the total number of diseases, $86 \%$ are injury-induced, of which muscle, tendon and joint pathologies account for $37 \%$. Most of injuries account for the front limbs and their distal segments, of which $10 \%$ are hoof disorders. Many of injuries in horses can be attributed to wounds, sores, and abrasions $(51,5 \%)$. Based on the type of equestrian sports, the highest injury incidence is reported in horses involved in triathlon (34\%). Among them, the greatest percentage $(25 \%)$ corresponds to injured tendons. Dressage horses have higher rates of muscle injury (24\%), with significant number of hoof disorders $(17 \%)$. In animals involved in pentathlon, the injury incidence rates reach $23 \%$, of which $30 \%$ are accounted for by wounds, $20 \%$ by abrasions and sores, and $11-12 \%$ by tendon, joint and hoof disorders.

In show-jumping horses, wounds account for $28 \%$ of injuries, abrasions and sores - for $24 \%$. As compared to horses involved in other sports, they are more likely to have injuries in the 
corners of the mouth, as well as to have injured back, coronets, front limb fetlock joints. High injury rate is also common for trotting horses running on racetracks (Kokoulina et al., 2012).

In a research of horses' health conducted in an equestrian school for 5 years, the injury rate increased from 4 to 29 cases per year with the same number of horses. The most common type of pathologies were wounds $(32,09 \%)$, damaged tendons and ligaments $(24,62 \%)$ and bruises $(19,40 \%)$ (Semenov, 2007). Equine back diseases are a major problem in sport horse breeding, considering that the pathology is reported in $99 \%$ of sport horses, no matter how expensive the saddle is.

According to K.R. Owen, for horses involved in different equestrian sports $46 \%$ of injuries occur in distal limbs. Thus, in show-jumping horses the incidence rate was twice as high as in horses which were not involved in competitions. In French trotting horses, $29 \%$ of limb disorders affected the metatarsal region. Injury forecast was different for horses used for different purposes, even if anatomically the same area was affected by injury (Owen et al., 2012).

\section{RESULTS AND DISCUSSION}

Injury incidence is common both in sport and prize horse breeding, therefore, selecting an appropriate treatment strategy is important. The horse's complete recovery follows a standard scenario: diagnosis, treatment and rehabilitation, i.e. adapting the musculoskeletal system to increasing training loads. This lengthy process depends on structural features of the equine body, theoretical and practical skills of coaches and sports veterinarians. Speeding the process up leads to adverse effects to the equine locomotor system that worsens the horse's athletic or prize career outlook (Kovach, 2009).

Brazilian scientists' study proved that the horse's athletic performance depends on the prevalence and predisposition to the locomotor system injuries. The data of 116 horses of various breeds and ages used in dressage, horse racing, polo, jumping, agricultural work and western riding performances were analyzed. All horses were examined with X-ray and/or ultrasound scanners. Dermatitis was more common in animals used in western riding than in draft horses. Fracture incidence was higher in race and polo animals than in draft horses. Defects of movement, lameness were more common in sports horses than in draft horses. Besides, the shoulder injury incidence rate decreased along with the intensity of horses' involvement in jumps. The incidence of lower limb tendon injury was lower in jumps than in dressage and in western riding.

It was established that there is a link between the injury location and type and physical load. Among racing horses where young animals predominate injury-induced orthopedic disorders are more common. As for the limbs, damage to the shoulder girdle was more often reported in racing horses, polo ponies, show-jumping and draft horses; while competitions in dressage and western riding caused injuries mostly to the rear limbs (De Sousa et al., 2017).

Based on our analysis, to an extent any use of the horses may result in equine injuries, especially limb injuries for which cryotherapy is most often used. The application of this method also allows effective treatment of injuries to other parts of the equine body. Technically, cryotherapy refers to the use of cryogenic technologies for the treatment of horses with certain health issues, while cryostimulation is used for healthy horses (usually, for sport and racing horses). Therefore, in addition to cryotherapy healing effects, its rehabilitative applications are highlighted.

Thus, the studies conducted in the USA proved that the use of cryotherapy improved the horse's condition: muscle soreness was reduced, pain decreased, muscle performance improved. Positive effects on cardiac rhythm variability, increased aerobic reserve, and activity of the parasympathetic nervous system were observed (Cold therapy in horses..., 2018).

Cryotherapy sessions reduce blood flow to the affected area, which relieves swelling and decreases nerve conduction velocity, thus reducing pain. They are most effective within 48 hours after injury, but longer-term therapy also shows good results. Cryotherapy sessions usually take 15 minutes, with at least 30 minutes between the sessions conducted three to four times per day. Cryotherapy sessions for the treatment of acute injury are introduced immediately after the injury and within the first 48 hours. After this, cryotherapy may be useful 
on a reduced basis for the treatment of chronic injuries.

Most horses tolerate cryotherapy well and experience pain relief after treatment. Cryotherapy sessions can be used as a part of recovery program after the initial injury treatment to ensure increased blood circulation in the affected area after the session. Improved blood circulation in the affected area promotes healing and benefits the immune system.

Cryotherapy sessions may damage the tissue, if conducted for a long time without observing appropriate intervals. They are not suitable for animals with dermal grafts (The power of cold therapy, 2015). For open wounds that require tissue re-growth, cryotherapy can inhibit the process. Therapeutic cryotherapy sessions can be a preventive method regularly used after heavy exercise to restore blood circulation and prevent the muscles from heating up during workload. Thus, cryotherapy is commonly used to treat various injuries. Considering the injury prevalence in horse breeding, cryotherapy methods need to be more widely implemented in prize and sport horse breeding entities (Dorosh, 2007).

Arthritis (arthrosis) is a major problem in horse breeding. It is an inflammatory disease affecting the joint. This problem is particularly common in older horses, some of which represent the nuclear stock. In addition, the number of aged sport horses is increasing (in major national teams globally the number of such horses exceeds $70.0 \%$ ). The etiology of arthritis varies, from infections to fracture. For this pathology, cryotherapy sessions are especially effective during acute phase of disease, in case of an injury or sudden relapse. The session is conducted in the first three to four days and promotes reduced swelling, early termination of inflammatory processes, as well as relieves pain in the affected area (Westfall, 2014).

With intense muscular loads, microtraumas often arise, which, with mild clinical signs, are practically not diagnosable. As a result, chronic processes that predispose to more serious injuries develop in the damaged tissues. Many owners and trainers of horses of the prize and sports areas considered tendon and ligament injuries as potentially more dangerous for a horse's future sporting career than fractures. The main reason is the problem of timely detection of tendinitis. As a rule, in the initial stages of damage to the tendons and ligaments appear in the form of implicit clinical signs, often associated with soft tissue damage. Therefore, in the absence of suitable diagnostic equipment and experienced personnel for diagnostic ultrasound, detection of damage to tendon ligaments is carried out at those stages when tendon healing and complete healing become unlikely (Skripnik, 2015).

Current trends in sports rehabilitation of horses of the prize and sports areas include the initial period of rest, nonsteroidal anti-inflammatory drugs, the use of physiotherapy techniques, where cryotherapy is of great importance along with the use of passive or active training after changing and adapting its modes (Semenov, 2007).

\section{CONCLUSIONS}

At the end of the 20th century, cryotherapy technologies became widely applied in health care, and then in veterinary practice. Two main types of cryotherapy include whole-body and local cryotherapy, which differ in the impact, applications and efficiency. Based on the above in the article, we propose a maximum rehabilitation period, as a rule, in the fall, after the end of the sports season. We suggest that competing and triathlon horses be removed from jumps and freed from large gallops, dressage horses from difficult (and sometimes from any) elements already at the initial stage of rehabilitation with simultaneous initiation of cryo-procedures. Of course, the duration of all these periods is influenced by the age of the horse, its fitness, the level of sports potential. There is not a very large group of age "cup" horses, which must be very delicately "led" from tournament to tournament, only maintaining and, if possible, increasing their preparedness. These horses are true aphorisms "do less" or "every jump brings a competitive horse to retirement". For horses of this group, cryotherapeutic procedures are preferably carried out on a smaller scale and on an ongoing basis. 


\section{ACKNOWLEDGMENTS}

The authors are grateful to the PE "KRIOKOMPLEKT", in particular its director Aleksandr Kravchenko and sales manager Roman Makarenko for the informational and financial support during the research.

\section{REFERENCES}

Alarming statistics: in smooth jumps, not everything goes smoothly, 2018. Available in: <https://news.sportbox.ru/Vidy_sporta/horse_wo rld/spbnews_NI835566_Trevozhnaja_statistika_ v_gladkih_skachkah_ne_vse_idet_gladko>.

Accessed in: 15 Fbr 2019.

BARANOV, A.Y.; KIDALOV, V.N. Cold treatment. Cryomedicine. Saint Petersburg: Aton, 1999. 470p.

BARANOV, A.Yu.; KUNGURTSEV, S.V.; MALYSHEVA, T.A. Fundamentals of cryotherapy for the training of top-level athletes, 2011. Available in: <http://www.sportmedicine.ru/medforsport2011-papers/baranov.php>. Accessed in: 15 Fbr 2019.

CARLSON, C.S.; CULLINS, L.D.; MEUTEN, D.J. Osteochondrosis of the articular-epiphyseal cartilage complex in young horses: evidence for a defect in cartilage canal blood supply. Veter. Path., v.32, n.6, p.55, 1995.

CHOLEWKA, A.; WOJCIK, M.; STANECK, A et al. Does local cryotherapy improve thermal diagnosis similar to whole-body cryotherapy in spinal diseases? J. Therm. Anal. \& Calorim., v.127, n.2, p.1155-1162, 2017.

Cold therapy in horses - procedure, efficacy, recovery, prevention, 2018. Available in: <https://wagwalking.com/horse/treatment/coldtherapy>. Accessed in: 15 Fbr 2019.

DE SOUSA, N.R.; LOUREIRO LUNA, S.P.; PIZZIGATTI, D. et al. Relation between type and local of orthopedic injuries with physical activity in horses. Ciênc. Rural, v.47, n.2, art.e20151218, 2017.

DINESH, S. Cryotherapy - an inevitable part of sports medicine and it's benefits for sports injury. Int. J. Appl. Res., v.1, n.4, p.324-327, 2015.
DOROSH, M.V. Diseases of horses. Moscow: Veche, 2007. 350p.

GEROEVA, I.B.; GLUSHKOV, V.P.; KRYLOV, N.A. The first results of the use of general air cryotherapy. Res. Bull., v.6, n.33, p.38-39, 2005

HERRMANN, F.; PESENATTO, G.G.; GOLDANI, E. et al. The use of alternative experimental models on microsurgery technique's training for medicine undergradute students. Period. Tche Quim., v.14, n.27, p. 117122, 2017.

Horse injuries, their prevention and treatment, 2014. Available in: <http://kohuku.ru/veterinariya/nezaraznye/4370travmy-u-loshadey-ih-profilaktika-ilechenie.html>. Accessed in: 15 Fbr 2019.

Injuries to horses at US hippodromes decreased, 2016. Available in: <http://www.hippodrom.ru/modules/AMS/article .php?storyid=1057>. Accessed in: 15 Fbr 2019.

KALASHNIK, I.A. Non-contagious diseases of horses. Moscow: Agropromizdat, 1990. 764p.

KOKOULINA, S.V.; SHESHINA, E.V.; SHILOVSKAYA, K.A. Study of the causes of horse injuries in an equestrian school and development of methods for their prevention. Inform. Techn. Manag. \& Econ. Econ. Sci., v.2, n.2, 2012. Available in: <http://itugtu.ru/en/исследование-причин-травматизмалош/>. Accessed in: 15 Fbr 2019.

KOVACH, M. New methods. Equestr. World, n.1-2, p.92-96, 2009.

OWEN, K.R.; SINGER, E.R.; CLEGG, P.D. et al. Identification of risk factors for traumatic injury in the general horse population of northwest England, Midlands and north Wales. Eq. Veter. J., v.44, n.2, p.143-148, 2012.

RUSSILLO, Ch. The benefits of cold therapy for sport horses. Dress. Tod., 2018. Available in: $<$ https://dressagetoday.com/horse-health-/thebenefits-of-cold-therapy-for-sport-horses>. Accessed in: 15 Fbr 2019.

SEMENOV, B.S. Horses injury. In Care, feeding and diseases of horses. Saint Petersburg: Lan, 2007. 420p. 
SKRIPNIK, I. All about horses. The complete guide to proper care, feeding, maintenance, dressage. Moscow: AST, 2015. 360p.

The history of cryotherapy. Rocky Mountain Cryotherapy, 2018. Available in: <http://www.rockymountaincryotherapy.com/his tory-cryotherapy/>. Accessed in: 15 Fbr 2019.

The power of cold therapy, 2015. Available in: <http://www.

equusmagazine.com/management/chill-factor29633>. Accessed in: 15 Fbr 2019.
WESTFALL, S. Don't get stuck in a rut! Understanding training cycles keeps both you and your horse progressing, 2014. Available in: $<$ https://equinewellnessmagazine.com/trainingcycles/>. Accessed in: 15 Fbr 2019.

WÓJCIK, M. The use of physical therapy procedures in the treatment of soft tissue injuries in a horse: a case study. J. Veter. Sci. \& Med. Diagn., v.6, n.4, 2017. DOI: 10.4172/23259590.1000239. 